Gris 


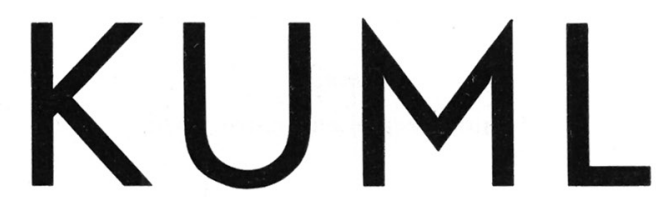

ÅRBOG FOR JYSK ARKÆOLOGISK SELSKAB

$$
1956
$$

With Summaries in English

UNIVERSITETSFORLAGET I AARHUS

1956 
Forside:

Grauballemandens højre hånd.

Redaktion:

P. V. G L O B

Copyright 1956

by

Jysk Arkæologisk Selskab

Printed in Denmark

by

Aarhuus Stiftsbogtrykkerie A/S

Clichéer :

Hammerschmidt - Århus 


\section{INDHOLD}

Harald Andersen: Afsked med ådalen ...................... 7

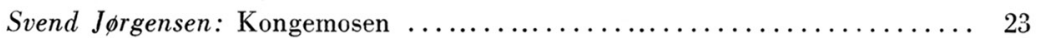

S. Vestergaard Nielsen: Vindblæs-fundet $\ldots \ldots \ldots \ldots \ldots \ldots \ldots \ldots \ldots \ldots$. 41

C. J. Becker: Fra Jyllands ældste jernalder .................... 50

Oscar Marseen: Oldtidsbrønde .......................... 68

Haakon Hougen: Vindumhede-fletningene og kjærlighetsknop ......... 86

P. V. Glob: Jernaldermanden fra Grauballe .................... 99

Svend Jørgensen: Grauballemandens fundsted ............................. 114

Willy Munck: Patologisk-anatomisk og retsmedicinsk unders $\varnothing$ gelse af mose-

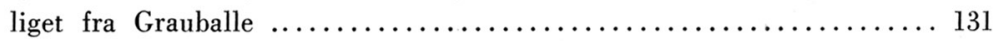

Carl Krebs og Erling Ratjen: Det radiologiske fund hos moseliget fra Grau-

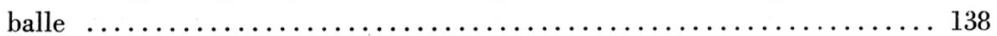

C. H. Vogelius Andersen: Forhistoriske fingeraftryk ............. 151

G. Lange-Kornbak: Konservering af en oldtidsmand .............. 155

Henrik Tauber: Tidsfæstelse af Grauballemanden ved kulstof-14 måling . . . 160

P. V. Glob: Et nybabylonisk gravfund fra Bahrains oldtidshovedstad ..... 164

Harald Andersen: »- Der skal ikke lades sten på sten tilbage« ......... 175

Peder Mortensen: Barbartemplets ovale anlæg .................. 189

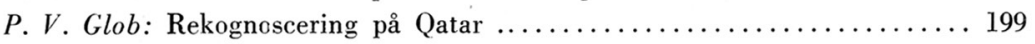

Jysk Arkæologisk Selskab ............................ 203

\section{CONTENTS}

Harald Andersen: The Weapons in the Illerup Valley .............. 21

Svend Jørgensen: Kongemosen - A Mesolithic Site in the Bog Aamosen,

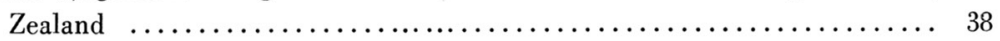

S. Vestergaard Nielsen: Vindblæs - A West Himmerland Bronze-Smithy .. 48

C. J. Becker: A Pre-Roman Iron Age Cemetery at Nim in East Jutland ... 65

Oscar Marseen: Prehistoric Wells .......................... 83

Haakon Hougen: How and Why the Knot in the Vindumhede Plait was tied

- and two Related Norwegian Knots ................... 97

P. V. Glob: The Iron Age Man from Grauballe ................ 111

Svend Jørgensen: The Finding-Place of Grauballe Man ............ 128

Willy Munck: Pathological-anatomical and Forensic-medicinal Investigation

of the Peat-bog Body from Grauballe ................... 136

Carl Krebs and Erling Ratjen: The Radiological Examination of the Peat-

bog Body from Grauballe ........................ 150

C. H. Vogelius Andersen: Prehistoric Fingerprints ................. 154

G. Lange-Kornbak: Grauballe Man - the Conservation Process ......... 158

Henrik Tauber: Dating of Grauballe Man by Carbon-14 Measurement ...... 163

P. V. Glob: A Neo-Babylonian Burial from Bahrain's Prehistoric Capital .. 172

Harald Andersen: The Building by the Barbar Temple ............... 186

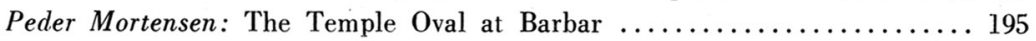

P. V. Glob: Reconnaissance in Qatar ............................ 201 


\title{
PATOLOGISK-ANATOMISK OG RETSMEDICINSK UNDERSØGELSE AF MOSELIGET FRA GRAUBALLE
}

\author{
Af WILLY MUNCK
}

D. 12/5-52 foretoges udvendig unders $\varnothing$ gelse af liget liggende i den stilling, hvori det fandtes i mosen, d. v. s., at man begynder unders $\varnothing$ gelsen med inspektion af ligets bagflade.

Huden er overalt mørkebrun, føles meget fast, ligesom garvet, og den er ofte noget foldet.

Liget ligger på maven med hovedet drejet let til højre. Ryggen vender næsten lige opad, men der er en fremefter krumning i rygs $\varnothing j$ len.

Hovedet er fladtrykt, skraat bagfra fra højre fremad mod venstre; navnlig er højre side af baghovedet meget fladt. Paa issen en del halvlange, rødlige hår. Knoglerne føles ikke tydeligt brækkede, men nærmest som om de var affladede ved tryk, efter at de er blevet bløde og bøjelige. Øjnene er lukkede.

Man ser ingen læsioner på bagsiden af halsen, spec. ingen snørefurer.

H申jre arm ligger lidt skudt op i skulderen, og overarmen ligger lidt ud fra kroppen. Overarmsbenet føles ikke knækket. Albuen er bøjet, og underarmen er drejet således, at håndfladen vender bagud. Knoglerne i underarmen føles hele. Fingrene er ret lange og slanke, neglelejerne ret smalle, men selve neglene mangler. Ingen synlige sår $\mathbf{i}$ huden.

$V$ enstre arm ligger ned langs kroppen. Overarmsbenet er ikke brækket, albuespidsen er skubbet lidt opad, og der er en lille defekt i huden på bagsiden af leddet. Ingen ledskred. Underarmsknoglerne er hele. Hånden er knyttet med fingrene ned i hånden. Der er negl på 2. og 3. finger.

Bakkenet er stærkt drejet, således at $\mathrm{h}$. hofte vender fortil og v. bagtil.

Hфjre ben er stærkt bøjet i hoften og navnlig i knæet, som er spidsvinklet bøjet, og højre fod ligger ned under nederste del af venstre lår. Højre femur føles ikke brækket.

Venstre ben er mere strakt. V. lårben er brækket ca. $10 \mathrm{~cm}$ nedenfor lårbensknuden, og hele venstre lår er meget stærkt fladtrykt på den opadvendende side.

Der er skråbrud af venstre skinneben ca. $15 \mathrm{~cm}$ nedenfor knæet med en spids nedad og medialt. Det nederste brudstykke er lidt forskudt opad. V. fod synes ikke brækket.

D. 21/5-52 fortsættes med unders $\varnothing$ gelsen af liget, efter at dette er vendt om. Liget ligger nu på ryggen, idet man dog stadig har bevaret den oprindelige 
stilling. Hovedet er bøjet noget bagover og drejet lidt til højre. I venstre side af panden findes et indtrykket, let exkaveret parti med en diameter på $10 \mathrm{~cm}$. Den nederste rand af dette parti ligger $4 \mathrm{~cm}$ ovenfor venstre $\varnothing \mathrm{je}$, og den inderste rand når til midtlinien. Huden er rynket og foldet på h. side af hovedet, men glat $i$ det meste af panden. På venstre side af hovedet findes en større dusk hår, hvis længde er op til ca. $15 \mathrm{~cm}$. Venstre $\phi$ reflip er godt bevaret opadtil, medens der nedadtil i nærheden af фreåbningen er nogle uregelmæssige defekter, som ser ud til at være fremkommet efter d $\varnothing$ den. Øjnene er noget sammenknebne, og фjeæblerne er helt affladede og indtørrede. Iris farve kan ikke sikkert bed $\varnothing$ mmes, men det er mest sandsynligt, at $\varnothing$ jnene har været ret mørke. Der er ingen фjenbryn. På venstre side af næseryggen opadtil findes en $1 \mathrm{~cm} \mathrm{lang,}$ lodret defekt i bunden af hvilken man føler næsebenene, der synes at være løsnede fra hinanden. Næsen er noget fladtrykt, nærmest trykket noget over imod højre. Der er også en defekt nedenfor nederste del af v. фje. Randene af begge defekter er noget tjavsede, og man føler igennem defekten v. kindben, og overkæbebenet er løsnet opadtil. Munden står lidt åben, ser ud til at være ret stor. I overkæben findes $4+$ og $+3-4-5$, i underkæben $\div$ 1-2-3-4-5. Tænderne er meget sorte og afslidte på tyggefladen. Der findes enkelte skæghår på overlæben af en længde på fra $2-3 \mathrm{~mm}$ til næsten $1 \mathrm{~cm}$ og ligeledes på hagen, hvor hårene er mere rigelige.

Opadtil på forsiden af halsen findes en stor defekt, hvis фverste rand begynder $5 \mathrm{~cm}$ nedenfor og ca. $3 \mathrm{~cm}$ bagved højre $\varnothing \mathrm{re}$, og som løber opad og fremad langs med eller snarere lidt ovenfor underkæberanden (se figur 1-2). Denne rand er ret skarp. Fortil går randen $2 \mathrm{~cm}$ bagved hagespidsen, og på venstre side forløber randen omtrent også langs med underkæberanden, og v. sårvinkel ligger ved nederste del af v. øre. Her er defekten meget uregelmæssig. Nederste sårrand går fremad nedad, er opadtil ret glat, men på midten findes $\mathrm{i}$ hvert fald et hak, hvorefter sårranden forløber ganske glat. Defekten er meget gabende, fordi huden åbenbart er skrumpet således, at dens rand er trukket nedad sammen med den nederste del af sårbunden. Opadtil i defekten er der en stor åbning ind til munden, således at tungen ligger blottet. Man føler et hul op i den bageste del af den hårde gane, og man kan let komme op i næse-svælgrummet. Tungen er stærkt sammenskrumpet, men dog så velbevaret, at formen nogenlunde kan erkendes, således at der også er en tungespids. Under tungen går defekten helt ind til hvirvels $\varnothing j$ len, og man føler her opadtil bunden af hvirvellegemet af vistnok 2. hvirvel. Lidt længere ned i defekten findes en gabende spalte mellem 3 . og 4. hvirvel, og man ser stykker af de forreste senebånd, mellem hvilke der er en længdespalte. Bagtil i nederste del af sårbunden findes strubelåget, som er ganske velbevaret, og bag det kan man dels komme ned i struben og dels i spiserøret, som er overskåret totalt, og man genfinder også den $\emptyset$ verste ende af spiserøret i фverste del af sårbunden bagtil. Man føler nedenfor strubelåget og tungebenet og nedenfor dette igen skjoldbrusken. Man kan ikke erkende noget, som ligner snørefurer på halsen. Der ses ingen defekter længere nede på halsen. Højre skulder er skudt noget opad. Højre overarm ligger noget ud fra kroppen med albuen retvinklet bøjet og med bagsiden af underarm og hånd fremefter. Der findes en lille defekt $\mathrm{i}$ huden ud for leddet mellem overarmen og radius, men 


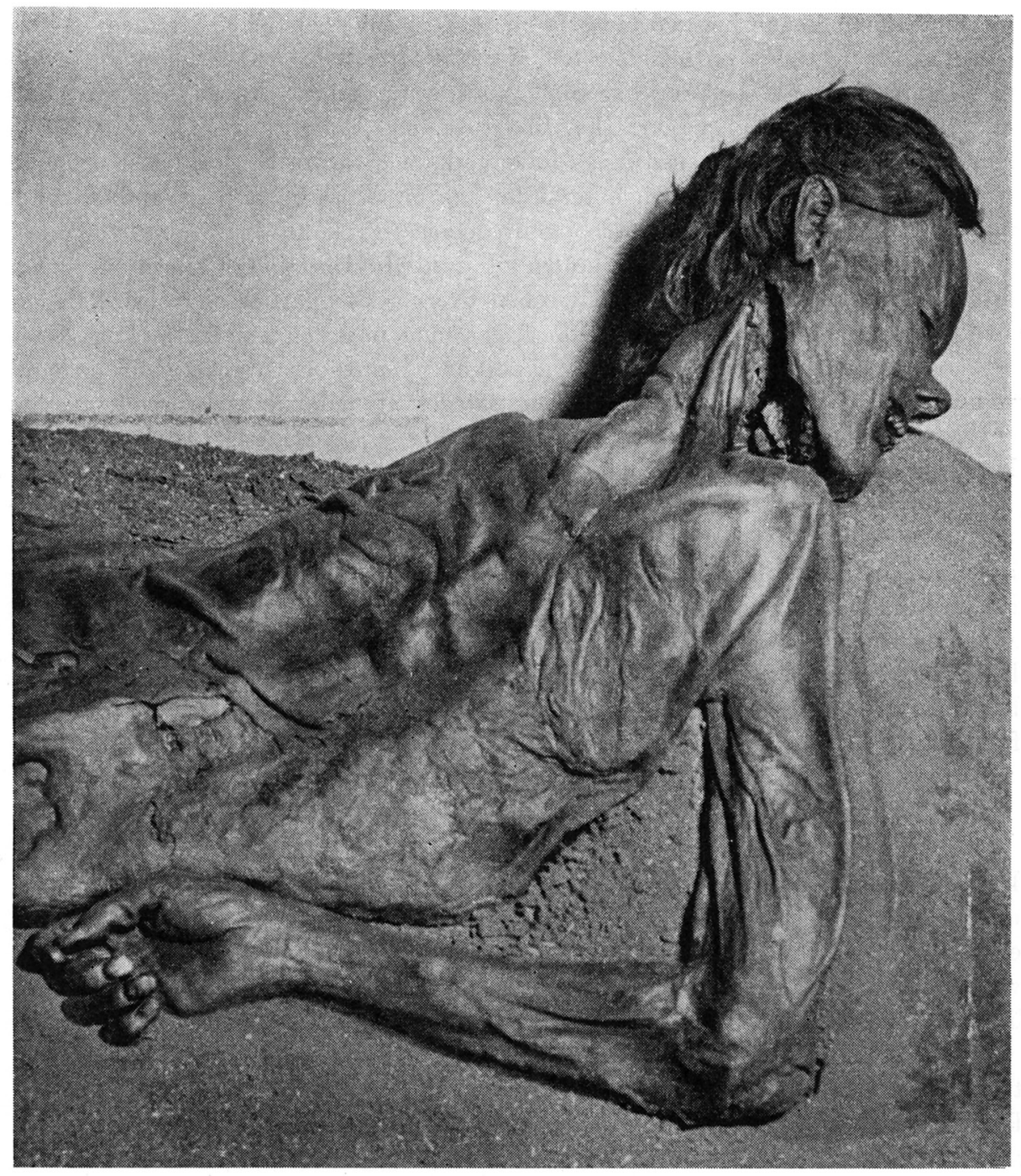

Fig. 1. Grauballemanden med overskåret hals. Grauballe Man with throat cut.

der ses ingen forskydning i leddet, og defekten er utvivlsomt opstået efter døden. Armen er iøvrigt meget fladtrykt, og man føler meget lidt bløddele under den brune, ligesom garvede hud. Ingen brud af hverken overarmen eller underarmen, men midt på højre overarms-ben ses en fortykkelse og ligesom en let vinkelbøjning bagud tydende på et tidligere brud. Venstre arm ligger ind imod kroppen, og her er lidt forskydning i albuen opefter. Der føles intet brud af knoglerne $\mathrm{i}$ venstre arm.

Brystkassen er stærkt fladtrykt, og navnlig ses en ret dyb fure lidt til venstre 
for midtlinien. Begge brystvorter er velbevarede. Ingen defekter $i$ huden på forsiden af brystet, men på nederste del af brystet på højre siderand og også lidt på venstre siderand ses uregelmæssige defekter på grund af vævshenfald. Også underlivet er stærkt fladtrykt. Der findes en stor, meget uregelmæssig defekt bagtil i højre lyskeegn og ned langs inderste kant af højre lår, og i denne defekt ses skambenssammenføjningen, hvor de to ben er løsnet og højre skamben skudt noget bagud. Randene er tjavsede og uregelmæssige.

Højre ben er stærkt bøjet i hoften og spidsvinklet bøjet i knæet og ligger drejet således, at lårets indside hviler hen over bækkenpartiet og venstre underarm, mens højre fod med sin indside ligger mod indsiden af venstre knæ. Også hele højre ben er stærkt fladtrykt, og der er på indsiden af højre lår nedadtil ved knæet ret stærkt henfald af huden, således at nederste lårbensende næsten er blotlagt. Højre fod er godt bevaret, navnlig er trædepuderne særdeles velbevarede på hele fodsålen. Ingen negle.

Venstre ben ligger drejet noget udefter og er strakt også $\mathrm{i}$ foden. Det er stærkt fladtrykt. Af venstre lårben findes den фverste halvdel let krummet, men i nederste halvdel kan man ikke tydeligt føle benet. Her er vævet $i$ det hele meget blødt. Kun nedadtil føles c. $10-15 \mathrm{~cm}$ af benet ovenfor leddet. Opadtil på forsiden og indsiden af venstre underben findes en ret stor, næsten $20 \mathrm{~cm}$ lang, laset defekt $\mathrm{i}$ huden, og her ser man skinnebenet ligge blottet; det er blødt og bøjeligt, tilsyneladende uden kalk og er brækket skråt over med nogen opadforskydning af nederste brudstykke.

Den indvendige unders $\varnothing$ gelse foretages således, at der lægges snit fra lidt under midten af brystbenet og ned til symfysen, og det forlænges udefter i højre lyskeegn, hvor der $\mathrm{i}$ forvejen er et sår. Man åbner ikke kraniet, da man mener derved at måtte molestere hovedet på en sådan måde, at den senere museumsopstilling af liget vil фdelægges.

I brystkassen ses begge brysthuler fladtrykte, og i begge sider ses nogle fladtrykte rester af lungerne, som ikke synes at være fastvoksede til brystvæggen. På hjertets plads kan kun erkendes nogle bløde, brune, usammenhængende masser, som ikke kan bedømmes. De store kar kan ikke erkendes.

I underlivet ser man på leverens plads en fladtrykt ca. $15 \times 10 \mathrm{~cm}$ stor masse med nedad afrundet kant og tydelig overtrukket af en kapsel; ved indsnit deri ses en blød, rød masse. Mavesakken kan ikke isoleres. Milten, bugspytkirtelen, binyrerne og nyrerne heller ikke.

Tarmen tages ud som en samlet klump, og den indeholder en grødet, mørkt brunrød masse.

Urinlederen og urinblaren kan ikke erkendes.

I pungen kan man isolere et fladt legeme, som formodes at være testis.

Det skal bemærkes, at man ved åbningen af underlivet finder, at der mange steder er tynde, grenede strænge, der ligner planterødder.

Rygsøjlen viser intet brud, men der er lidt løshed imellem hvirvlerne.

Bakkenet er lidt fladtrykt, og der er løsning fortil i symfysen. 
Kraniet er som omtalt ikke åbnet, og man skal henvise til, hvad der er fundet på røntgenoptagelserne af kraniet.

Mikroskopisk unders $\varnothing$ gelse er fors $\varnothing$ gt foretaget af følgende væv:

1) Vaev fra leverens plads: en trådet ubestemmelig masse. Leverceller kan ikke erkendes. Der ses lidt bruskvæv, antagelig fra ribbensbrusk.

2) Vaev fra abdomen: ubestemmeligt væv.

3) Vav fra lungernes plads: ubestemmeligt væv, hist og her bindevævsstrøg.

4) Muskelvaev: do.

5) Testes: aflangt stk. En tyk bindevævskapsel indeholdende et væv med lidt fladtrykte hulrum, som kan være testiskanaler. I den ene ende et parti, der i opbygning ligner epididymis, dog uden epitel.

Endvidere er foretaget undersøgelse af hårpr $\varnothing v e r$, som er unders $\emptyset \mathrm{gt}$ i glycerinindlejring.

Hovedhår viste: Skeden gennemgående utydelig. Håret middeltykt. Barken er ret kraftigt brunligt pigmenteret, dels som ganske fine småpletter, dels som en mere diffus farve, som næppe har været hårets oprindelige farve, sv. til at man almindeligvis finder rødligt hår på gamle moselig.

Marv findes nogle steder i små mørke klatter, andre steder mere som en ubrudt stræng i midten af en bredde af lidt under halvdelen af hårets. Enderne er let flossede.

Skceghårene er noget tykkere end hovedhårene. Marven er næsten halvdelen af hårets tykkelse, dog lidt svingende i bredde.
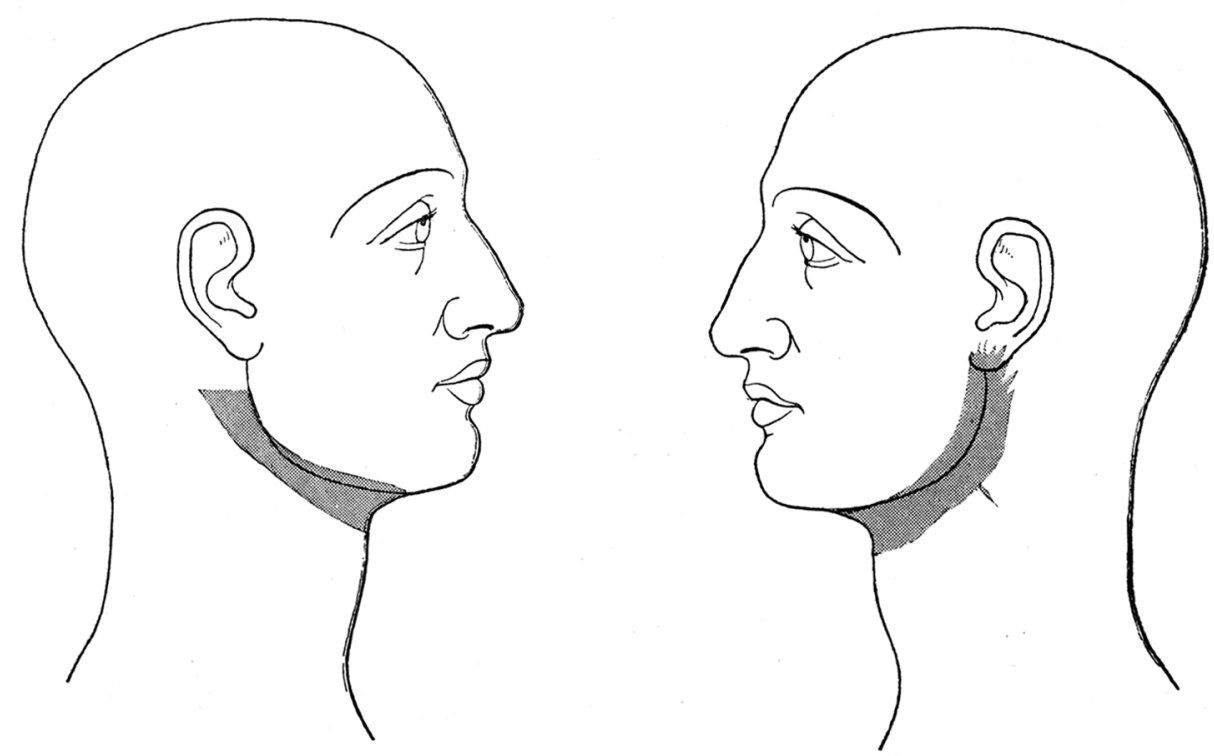

Fig. 2. Skematisk tegning af den gennemskårne hals på Grauballemanden. Schematic drawing of Grauballe Man's cut throat. 
Efter resultatet af unders $\varnothing$ gelserne kan man slutte følgende:

Det ganske usædvanligt velbevarede lig har på grund af den særlige beskaffenhed af jordbunden, hvori det har ligget, gennemgået en konserveringsproces, som nærmest gør indtryk af at være en garvning. Denne har gjort huden fast og modstandsdygtig og har i høj grad modvirket de forskellige, normalt hurtigt efter døden indtrædende opl $\varnothing$ sningsprocesser. Dog har de indvendige bløde organer ikke kunnet bevares. Samtidig har knoglerne været udsat for en afkalkningsproces, hvorved de er blevet bløde og har kunnet bøjes og fladtrykkes, hvad der bl. a. har været tilfældet med hovedets knogler.

Knoglebygningen og hårets forhold g $\phi \mathbf{r}$ det overvejende sandsynligt, at det drejer sig om en mand, og tændernes forhold tyder på, at det har drejet sig om et individ noget op $\mathrm{i}$ årene.

Der er på forsiden af halsen fundet en stor defekt strækkende sig fra det ene $\varnothing$ re til det andet. Den ligger ret højt oppe på halsen, randene er temmelig glatte, men nederste sårrand har et hak på midten. I sårbunden er svælget bredt åbent, og der er en gabende spalte mellem 3. og 4. halshvirvel.

Denne defekt må sikkert opfattes som en snitlæsion, formentlig frembragt ved flere snit af en anden person. Defektens retning og $\emptyset$ vrige udseende tyder mod, at det skulle dreje sig om en selvlæsion eller en tilfældig læsion opstået efter d $\phi$ den.

De фvrige læsioner, således bruddene af venstre lårben og skinneben, nogle forskellige defekter $\mathrm{i}$ ansigtet og den omtalte fladtrykning af hovedet, må antages opstået efter d $\varnothing$ den.

Tegn på sygdom har ikke kunnet påvises.

Den mikroskopiske unders $\varnothing$ gelse har ikke givet nogen oplysninger.

Hårundersøgelsen tyder på, at personen har været mørkhåret. Den rødlige farve skyldes antagelig ligets henliggen i mosejord, således som det er observeret ved flere tidligere fund af moselig.

\section{SUMMARY \\ Pathological-anatomical and Forensic-medicinal Investigation of the Peat-bog Body from Grauballe.}

[The article opens with a detailed forensic-medicinal description of the exact condition of the body in its original position (taken 12th May 1952) and when turned onto its back (taken 2lst May 1952), followed by a detailed description of the interior of the body after opening. The skull was not opened out of consideration for future museum exhibition. After these descriptions follow the conclusions, which are here translated in full.]

As a result of these investigations the following conclusions can be reached:

This most unusually well preserved body has, as a result of the particular composition of the earth in which it has lain, undergone a process of conservation which appears to resemble most closely a tanning. This has made the skin firm and resistant and has to a high degree counteracted the various processes of decay which normally commence soon after death. The soft inner organs have, however, not been able to survive, and at the same time the bones have been subjected to a decalcifying process which has left them soft and capable of being bent and flattened, as has happened, inter alia, with the bones of the head. 
The bone structure and the state of the hair make it very highly probable that the subject is an adult male, and the condition of the teeth suggests that he was an individual of somewhat advanced age.

On the front of the neck was found a large wound stretching from ear to ear. It lies fairly high up on the throat, and the edges are moderately smooth though the lower edge of the wound shows a cut in the centre. In the interior of the wound the gullet gapes wide open, and there is a wide gap between the 3rd and 4th vertebrae of the neck.

This wound may with certainty be interpreted as an incised lesion, probably caused by several cuts inflicted by a second person. The direction of the wound and its general appearance makes it unlikely that it could be self-inflicted or accidentally inflicted after death.

The other lesions, comprising breakages of the left thigh-bone and shine-bone, various wounds in the face, and the flattening of the head already remarked, may be assumed to have taken place after death.

No sign of disease could be detected.

The microscopic investigation has added no material facts to our information.

The investigation of the hair suggests that the subject was dark-haired. The reddish coloration is presumably accounted for by the body having lain in peat, and has been observed in the case of several other discoveries of peat-bog bodies.

Willy Munck. 